\title{
El origen del PROYeCto turístico Cancún, MéXico. UNA VALORACIÓN DE SUS OBJETIVOS INICIALES A 42 AÑOS DE SU NACIMIENTO
}

\author{
The Effects of Tourism in Cancún, Mexico from its Beginnings to the Present. \\ An Analysis of the Last 42 years \\ Horacio Espinosa-Coria
}

Resumen: A finales de los años sesenta del siglo XX, oficiales del Banco de México fomentaron el turismo para contrarrestar algunos de los efectos negativos de una estrategia de crecimiento económico, basada en la industrialización a través de la sustitución de importaciones. El análisis del contexto que dio surgimiento a Cancún y de los cambios demográficos, económicos y sociales ocurridos con su crecimiento, permite valorar con mayor objetividad el cumplimiento de los objetivos que originalmente tuvo el proyecto Cancún. Ello hace posible, asimismo, interpretar la visión de desarrollo que los promotores de este proyecto tuvieron. En síntesis, al observar la distribución sectorial del PIB del estado de Quintana Roo, la concentración geográfica de éste, y el empleo y divisas generadas por el turismo, se concluye que algunos de los propósitos iniciales que dieron vida a Cancún se han cumplido, en tanto que otros han tenido el efecto contrario al esperado.

Palabras clave: turismo, desarrollo regional, empleo, migración.

Abstract: By late 1960s Banco de México officials promoted tourism as a way of counterbalancing some negative effects of a growth economic model based on industrial import substitution (ISI). By looking at the historical context within which Cancun was built, it is likely to assess the developmental intentions of those who advocated tourism. The Banco de México officials advanced a notion of progress which can be grasped by taking into account some of the demographic, economic and social impacts of the Cancún project. In summary, the composition of Quintana Roo's Gross Domestic Product, it's geographical distribution, tourism employment and foreign exchange earnings, indicates that Cancún came to fullfill part of it's founding goals. Other objectives, however, were not achieved.

Keywords: tourism, regional development, employment, migration.

Horacio Espinosa Coria, doctor en Política por la Universidad de York, Reino Unido. Profesor-investigador de la Universidad de Quintana Roo, campus Playa del Carmen. Temas de especialización: política pública y turismo en México. Correo electrónico: hespinosa@uqroo.mx.
Enviado a dictamen: 03 de septiembre de 2012 Aprobación: 18 de diciembre de 2012 Revisiones: 1 


\section{Introducción}

$\amalg$ presente trabajo tiene dos objetivos principales: esclarecer el nacimiento del proyecto Cancún hacer una evaluación de éste a partir de las metas que sus impulsores se plantearon. Ello obliga a hacer una revisión histórica del estado de la economía y la población del país entre los años cuarenta y sesenta del siglo XX, así como a destacar la visión que las élites políticas de ese tiempo tenían sobre el desarrollo económico y la forma de enfrentar los problemas para conseguir este último. Visto así, este estudio es una interpretación más cabal del surgimiento de Cancún, cuyo peso actual en el perfil productivo, poblacional y geográfico del estado de Quintana Roo justifican su examen. Aunque este análisis no pretende explicar un fenómeno por el conjunto de ideas - teoría- que lo interpretan, y por consiguiente no busca reformularlas, sí en cambio pretende conocer y valorar los impactos que el proyecto Cancún ha tenido en tanto medio para generar divisas, crear empleo e impulsar el desarrollo regional, los fines que le dieron quienes lo diseñaron e impulsaron. Esto supone, no obstante, dejar de lado otros efectos, como los ambientales —contaminación y uso no racional de recursos naturales-, culturales — valores e identidades de grupo-y algunos de corte social — violencia y desigualdad - los cuales han sido abordados en otros trabajos. ${ }^{1}$ En síntesis, se escogió Cancún como tema de estudio por su importancia histórica y se toman ciertas pruebas empíricas para con ellas valorar algunas de las consecuencias de la idea de progreso que tenían los agentes que la materializaron.

\section{Desarrollo industrial, decadencia rural y concentración urbana en México}

A partir de 1940 las élites gobernantes en México aceleraron el proceso iniciado por la administración cardenista (1934-1940) para conformar un mercado interno mediante el apoyo a la agroindustria y la producción manufacturera (Hernández, 2002: 386). Entre 1940 y 1980, México siguió un patrón de crecimiento orientado a fortalecer una planta industrial propia, ${ }^{2}$ como símbolo de innegable progreso caracterizado por una estructura productiva y social moderna. ${ }^{3}$ En ese lapso, el Producto Interno Bruto (PIB) creció a una tasa anual promedio del 6\% (Tello, 2007: 297, 366, 544). Aunque en un principio el sector agrícola fue el más dinámico, éste fue paulatinamente desplazado por un aparato industrial beneficiado por el establecimiento de instituciones y la aplicación de políticas impulsoras de su desarrollo. Así, entre 1940 y 1955 la agricultura creció un $7.4 \%$ anual, mientras las manufacturas lo hicieron un 6.9\%, y la electricidad y el petróleo un 6.8\%. En cambio, en la etapa de 1955 a 1970, la agricultura disminuyó su ritmo de crecimiento a 3\% anual, en tanto las manufacturas aumentaron a $8.6 \%$, y la electricidad y el petróleo subieron al $11.6 \%$ y al 9.2\% respectivamente (Solís, 1983: 169). La tendencia desfavorable hacia el sector primario se acentuó aún más, de tal forma que de 1970 a 1975 la agricultura creció anualmente tan solo 0.7\%\% (Solís, 1983: 169).

Los gobiernos del período 1940-1970 emplearon distintos instrumentos de política para favorecer el desarrollo de la industria, sin que este mismo tipo de herramientas se utilizara para apoyar al sector primario de la economía. Por ejemplo, en 1960 el apoyo de Nacional Financiera a las industrias básicas representó más de 50\% del total de créditos otorgados por dicho organismo gubernamental (Solís, 1983: 174). El fomento a la creación y consolidación de un aparato industrial local que produjera bienes que antes eran manufacturados en el exterior también se apoyó en el establecimiento de aranceles o cuotas a la importación. Se calcula que en 1966 el 60\%de los bienes importados estaban sujetos a control (Solís, 1983: 176).

El proyecto gubernamental de erigir una base industrial propia modificó sustancialmente el perfil de la economía, la sociedad y el territorio de la nación mexicana. Si en 1940 el agro empleaba al 65\% de la 
fuerza laboral y representaba más del 23\% del producto nacional bruto (PNB), para 1970 ocupaba menos del 50\% de la fuerza de trabajo y su participación dentro del PNB había bajado al 16\%. En cambio, las manufacturas elevaron su participación en el producto interno de 17.8\% al 26\%, llegando a emplear al 16\% de la fuerza laboral en 1970 (Hansen, 1978: 57). El creciente peso que fue adquiriendo la industria en el conjunto de la economía y la decadencia de las actividades agrícolas indujeron la migración del campo a la ciudad.

A fines de la década de los años sesenta del siglo XX, la Ciudad de México concentraba un cuarto de la producción nacional y alrededor del 50\% de la producción de las industrias química, textil y de alimentos (Hamnett, 1999: 261-262). La perspectiva de mejora económica y mayor calidad de vida que ofrecían los sueldos de las ciudades fue un factor que indujo a los habitantes del medio rural a abandonar este último. Se estima que en 1968 el 58\% de la población rural tenía un ingreso anual de 130 dólares, mientras que el porcentaje de habitantes urbanos con ese nivel de ingreso era de 16\% (Gollás y García, 1976: 424). En pocas palabras, el apoyo oficial otorgado al sector secundario de la economía y el gradual desinterés por las necesidades del campo, generaron una masiva migración a las urbes, en particular a la Ciudad de México. Esta última tenía 1700000 habitantes en 1940 y, 20 años después, contaba ya con 4870000 habitantes; es decir, entre 1940 y 1960, la población de la ciudad capital aumentó 177.1\% (Wilkie, 1970: 231).

\section{Desequilibrio en la balanza comercial, desempleo y exclusión social en México}

El déficit de la balanza comercial comenzó a ser un problema de gran preocupación para los funcionarios de la administración del presidente Gustavo Díaz Ordaz (1964-1970). Este desequilibrio fue resultado de la incapacidad de la planta industrial para sustituir la producción de otro tipo de bienes que no fueran los de consumo final. Si bien es cierto que para 1970 la producción local llegó a cubrir la demanda de este tipo de bienes, fue insuficiente en el caso de productos intermedios y bienes de capital (Enríquez, 1988: 25). La compra en el exterior de estos últimos representó el 55\% del total de las importaciones en 1929, pero para 1970 ese porcentaje aumentó al 90\% (Villarreal, 1977: 81). El saldo negativo de las cuentas comerciales de México se agravó aún más si se toma en cuenta que las transferencias de regalías al exterior y los intereses del capital foráneo, sumaron en promedio 500 millones de dólares anuales durante toda la década de los años sesenta (Villarreal, 1977: 81). De hecho, entre 1962 y 1970, el déficit comercial aumentó de 120 millones de dólares a 924 millones (Fernández y Rodríguez, 1985: 97).

El aumento acelerado de la población en ciudades como la capital del país fue de la mano de un aumento en el desempleo y del deterioro de las condiciones de vida. Se apostó por un esquema de industrialización que fomentó el uso de tecnología avanzada en la producción, en lugar de uno que privilegiara el uso más intensivo de la mano de obra. Fue así como se generó un proceso contradictorio, ya que se registraron altas tasas de crecimiento industrial a la vez que se mantenían elevados niveles de desocupación. De hecho, se llegó a estimar que tomando juntas la tasa de desempleo y de subempleo, éstas representaron entre el 40\% y el 50\% del total de la fuerza laboral (Tello, 1980: 76). Tan sólo en Ciudad de México había más de tres millones de desempleados en 1971 (Hellman, 1978: 88).

Desdela perspectiva oficial, el crecimiento económico impulsado por el desarrollo de la industria bastaría para que los beneficios llegaran de forma natural al conjunto de la población. Esta visión dejó completamente de lado el aspecto humano y antepuso el crecimiento económico al reparto de la riqueza. ${ }^{4}$ Los datos así lo muestran; por ejemplo, entre 1950 y 1957, el porcentaje del ingreso personal del 50\% de las familias más pobres del país declinó, al pasar su participación en el ingreso total del 19.1\% al 15.6\% (Hansen, 1978: 74). En contraste, 
en 1950 el 20\% del grupo de población con los ingresos más altos acaparó el 59.8\% del total, mientras que en 1963 ese porcentaje se incrementó al 62.6\% (Erfani, 1995: 781). Era pues evidente cómo el modelo de desarrollo hasta entonces seguido no sólo había agravado el desequilibrio de las cuentas externas del país, sino que no había podido incorporar grandes contingentes de la fuerza laboral al dinamismo industrial, a todo ello se sumaba un deterioro significativo de las condiciones sociales.

\section{Nacimiento del proyecto Cancún}

Dentro del conjunto de la administración pública mexicana, fueron los oficiales de instituciones como el Banco de México, quienes buscaban alguna estrategia que diera solución al déficit en la balanza de pagos a la vez que se promoviera el desarrollo regional. Como lo comenta el propio Guillermo Ortiz, gobernador de dicha institución entre 1998 y 2010, "hacia finales de la década de 1960, empezó a pensarse en el Banco de México en la posibilidad de crear polos de desarrollo turístico que contribuyeran a la captación de divisas y a estimular el desenvolvimiento económico de zonas atrasadas o aisladas del país" (Ortiz, 2009: 9). Altos funcionarios del banco, en particular quienes ocuparían la Dirección General, Rodrigo Gómez (1952-1970) y Ernesto Fernández Hurtado (1970-1976), junto a otros personajes clave de instituciones hermanas, como Antonio Ortiz Mena, entonces titular de la Secretaría de Hacienda y Crédito Público, convencerían al presidente de la República, Gustavo Díaz Ordaz (Martí, 1985: 18), de iniciar la construcción de Cancún, el primero de cinco polos turísticos en las costas mexicanas que serían la base de una nueva política pública de fomento al turismo. El propio presidente anunciaría dicha política en su discurso de informe de gobierno ante el Congreso en el año 1969: "En breve se implementará un importante programa integral turístico como medio para fortalecer el desarrollo regional. Su objetivo es no sólo atraer divisas sino emplear los recursos de las propias regiones para mejorar las condiciones de vida de sus habitantes" (MacDonald, 1981: 176).

El desarrollo del proyecto Cancún también obedeció a circunstancias locales que fueron decisivas para entender por qué se escogió la Península de Yucatán como el espacio para ensayar una política pública a favor del turismo a partir de la construcción de los Centros Integralmente Planeados. En los años sesenta del siglo pasado, las principales actividades productivas del entonces territorio y hoy día estado de Quintana Roo se encontraban en una situación crítica. La falta de un plan racional de explotación forestal había llevado al descenso de la producción maderera (Careaga, 1990: 237), en tanto que la reducción de la demanda externa del chicle provocó la baja en su producción (César y Arnaiz, 1998: 380). Esta última, que había alcanzado un auge en la década de los cuarenta, luego empezó a descender. Un documento del Banco de Comercio de 1969 registró un volumen de producción de tan sólo 600 toneladas en ese año (Careaga, 1990: 238).

La precaria situación del campo quintanarroense era aún más grave si se toma en cuenta que la producción de henequén, base importante de la economía de la región, se vio severamente afectada con la conclusión de la guerra de Corea (1950-1953). Además, debe considerarse un dato por demás significativo: estimaciones de las autoridades mexicanas ubicaban el rendimiento por hectárea del cultivo de maíz en Quintana Roo como el más bajo a nivel nacional (Fondo Nacional de Fomento al Turismo, 1988: 22). Así pues, se tenía un escenario dominado por el desempleo agrícola como consecuencia de la caída de la producción maderera, del chicle y del henequén. Como comentan César y Arnaiz (1998: 357), "la grave crisis regional por el ocaso de las maderas, el chicle y el henequén, generaban una situación compleja que podría derivar en un problema social agudo". Desde la visión gubernamental, el fomento del turismo en esta región marginada del país podría "aliviar la tensión social producida por la pauperización de los núcleos 
campesinos" (Martí, 1985: 16). No debe pasarse por alto que en 1963 había 238000 personas que dependían exclusivamente del cultivo del henequén (Dondé y Turrent, 2009: 22).

La situación del mercado turístico internacional fue un factor decisivo en el nacimiento del proyecto Cancún. En efecto, en ese tiempo las cuencas turísticas del Mediterráneo, el Caribe y el Pacífico, especialmente Hawaii, registraban altas tasas de crecimiento. Frente a esta tendencia positiva en el mercado mundial del turismo, México respondió con la creación de los cinco Centros Integralmente Planeados: Cancún, ubicado en la costa del Caribe y que competiría con las islas de esta cuenca, además de Ixtapa, Huatulco, Los Cabos y Loreto, estos últimos localizados en la costa del Pacífico y que aprovecharían la demanda internacional en esa región. ${ }^{5}$ El apoyo de agencias internacionales como el Banco Interamericano de Desarrollo (BID) facilitó los planes de las autoridades mexicanas, pues esta institución, al igual que el Banco Mundial, veía el turismo como una herramienta para promover el crecimiento y desarrollo de las naciones del llamado tercer mundo. El BID, por ejemplo, otorgó en 1970 al gobierno mexicano un primer crédito por 17 millones de dólares para la construcción del Centro Integralmente Planeado de Cancún (Dondé y Turrent, 2009: 35).

Desde la perspectiva gubernamental, con la construcción de un polo turístico en la costa de Quintana Roo se cumplirían los propósitos que se había planteado el INFRATUR (Fondo de Promoción de Infraestructura Turística), que en ese entonces era el fideicomiso del Banco de México encargado de delinear y llevar a la práctica el núcleo de la nueva política turística. En el caso particular de Cancún, al levantarse éste:

Se fomenta la creación de nuevas fuentes de trabajo, aprovechando que la zona... tiene un alto potencial turístico y que la Península de Yucatán cuenta con una importante población rural o semi-rural de bajos ingresos, con limitadas alternativas viables para el desarrollo de otras actividades económicas proveedoras de empleo.

Se impulsa el desarrollo regional a través de la diversificación de las actividades agrícolas, industriales, artesanales y comerciales.

Se incrementa la captación de una mayor corriente de turistas provenientes del exterior y con ello los ingresos de la balanza de pagos (Fondo Nacional de Fomento al Turismo, citado en Fernández de Lara, 2009: 167-168).

\section{Los logros de Cancún}

Para los oficiales del Banco de México, el turismo fue visto como un motor de crecimiento económico con un gran impacto en el desarrollo de vastas áreas marginadas del territorio nacional. Hoy se puede argumentar que se sobreestimaron algunos de los potenciales beneficios de la industria turística. Se asumió, por ejemplo, que la generación de empleos reduciría las desigualdades sociales y que los efectos multiplicadores que traería consigo el desarrollo turístico aminorarían las disparidades regionales (Brenner, 2005: 140). Sin embargo, se debió considerar que un buen número de los empleos que genera esta actividad son de baja calificación y de carácter temporal debido a la estacionalidad de la demanda, es decir, los tiempos o temporadas a los que está sujeta la llamada industria sin chimeneas (Lickorish y Jenkins, 2000: 248-249).

En 1970 empezaron los trabajos de construcción de Cancún, y con el paso de los años se convertiría en el símbolo de una nueva política pública en el sector turismo. En unas cuantas décadas, una franja costera prácticamente deshabitada se transformaría en un destino favorito en el gusto de millones de turistas nacionales y extranjeros, así como en un polo de atracción de inmigrantes en busca de una oportunidad de trabajo en la pujante industria turística. Cancún, cuyo aeropuerto internacional fue inaugurado en 
1973 (Martí, 1985: 60), llegaría después a posicionarse como la segunda terminal aérea más importante del país. En 2010 recibió 3827892 pasajeros en vuelos regulares internacionales, mientras que al aeropuerto de la Ciudad de México llegaron 4273953 pasajeros (Secretaría de Turismo, s/f).

En términos de infraestructura de alojamiento, Cancún rebasólas expectativas que se habían formulado. De acuerdo con la solicitud de crédito presentada al BID en 1969, para 1980 habría 3000 de hotel, aunque ya en 1984 el número de habitaciones sumaba 6106 (Dondé y Turrent, 2009: 40). La Secretaría de Turismo del Estado de Quintana Roo (SEDETUR) reportó que en 2011 la cifra era de 28417 cuartos (SEDETUR, s/f). En ese mismo año, la derrama económica de la industria turística de Cancún se calculó en 2920 millones de dólares, lo que representó el 50.2\% del total generado por dicho sector en el estado, incluyendo los restantes cinco principales puntos turísticos: Cozumel, Riviera Maya ${ }^{6}$ Isla Mujeres, Chetumal y Mahahual (SEDETUR, s/f).

No es exagerado afirmar que Cancún ha sido el motor del crecimiento económico del mismo estado. Entre 1970 y 1985, los primeros 15 años de vida de este Centro Integralmente Planeado, el PIB de Quintana Roo creció casi el triple (2.8 veces) que el PIB nacional; tan sólo la rama económica específica de restaurantes y hoteles creció de 86000 pesos en 1970 a 70430000 pesos en 1985, seis veces y media el crecimiento de esta rama a nivel nacional (SEDETUR, 2005). De acuerdo con Lozano (2010), entre 2003 y 2008 la proporción del PIB del municipio de Benito Juárez en el PIB estatal se mantuvo en $63 \%$. El dinamismo de Cancún ha hecho evidente la gradual diferenciación en la geografía estatal entre una zona norte cuya prosperidad contrasta con el rezago de otras localidades de las regiones centro y sur. En 1998, por ejemplo, el mencionado municipio de Benito Juárez, cuya cabecera es la ciudad de Cancún, registró un ingreso per cápita de 81820 pesos anuales, mientras que en los municipios de José María Morelos y de Lázaro Cárdenas fue de apenas
3800 y 2340 pesos respectivamente (SEDETUR, 2005). Según el censo económico 2009 del Instituto Nacional de Estadística, Geografía e Informática, del total de unidades económicas registradas en Quintana Roo, el municipio de Benito Juárez concentraba el 48.5\%, tenía el $53.5 \%$ de todo el personal ocupado en la entidad y reunía el 55.9\% de las remuneraciones totales en el estado (INEGI, 2009).

La población de Cancún creció a un ritmo impresionante. En 2010, el municipio de Benito Juárez tenía 661176 habitantes, lo que representó el 49.87\% de la población del estado (INEGI, 2010: 3). En un lapso de 40 años, lo que era un sitio despoblado pasó a albergar a la mitad de todos los habitantes de Quintana Roo. Aunque el municipio de Benito Juárez no registra el índice de crecimiento poblacional más alto de la entidad, sigue manteniendo un comportamiento incluso mayor al de la media estatal (ver tabla 1). Este aumento en el número de habitantes es resultado, en buena medida, de la inmigración; al respecto, cabe resaltar que, entre 1990 y 2000, Benito Juárez fue el municipio del estado con el porcentaje más alto de población residente nacida en otra entidad o país, al registrar $74.6 \%$ y $70.2 \%$ respectivamente, cifra muy por encima de la media estatal, de 57.0\% y 56.4\% (INEGI, 2000: 14).

\section{Cancún: los rostros de su desarrollo}

La vida económica del estado de Quintana Roo depende excesivamente del sector servicios, principalmente del turismo. En 2010 la estructura sectorial del PIB estatal se distribuía de la siguiente manera: sector primario, $1.1 \%$; sector secundario, $11 \%$; y sector terciario, $87.9 \%$. En este último sector destaca que únicamente las ramas "transporte, correos y almacenamiento", "servicios inmobiliarios y de alquiler de bienes muebles e intangibles" y "servicios de alojamiento temporal y de preparación de alimentos y bebidas", representaron el 37.2\% del PIB estatal (INEGI, 2011: 42). En términos de personal ocupado por sector de actividad económica, 
entre 2000 y 2010 el sector agropecuario vio disminuir su participación, al pasar de $9.9 \%$ a $6.8 \%$, el sector industrial sufrió una baja del $15.7 \%$ al $14.5 \%$, en tanto el sector comercio y servicios aumentó de $72.7 \%$ a 77\% (INEGI, 2010: 51). Dicho patrón se repite, aunque en una proporción mayor, en el municipio de Benito Juárez. Por ejemplo, en 2003 un 51\% del personal ocupado del municipio se concentró en tres de nueve ramas del sector servicios; éstas fueron "transporte, correos y almacenamiento" (7.6\%), "servicios de alojamiento temporal y de preparación de alimentos y bebidas" (20.4\%), y "comercio al por menor" (23\%). En cambio, las actividades "industria manufacturera" y "construcción" representaron el 5.1\% y el 4.2\% del personal ocupado, cifras inferiores a las de 1998: 5.3\% y 5.4\% (INEGI, 2003 y 2006).

Los datos sobre la distribución sectorial del PIB estatal y del municipio de Benito Juárez, lo mismo que el personal ocupado por sector de actividad, demuestran con toda claridad que no se consiguió el objetivo originalmente planteado de impulsar el desarrollo regional mediante la demanda de insumos y oferta de productos del centro nodal - el Centro Integralmente Planeado de Cancún-. Es más, se calcula que "el $97 \%$ por ciento de los insumos adquiridos por esta urbe provienen de otros estados del país y del extranjero" (Secretaría de Desarrollo Social, 2004: 7). Así, se confirma el fenómeno ya observado en otros polos turísticos, que es el de formar enclaves económica y socialmente separados de su hinterland o área de influencia (Brenner, 2007: 19). Esto último se constata, por ejemplo, dados los valores tan bajos que registran algunos indicadores económicos de los tres municipios que conforman la llamada Zona Maya: Felipe Carrillo Puerto, José María Morelos y Lázaro Cárdenas. Según el censo económico 2009 del INEGI, en ese año estas tres demarcaciones contribuyeron con el 6.5\% de las unidades económicas de toda la entidad, el 2.9\% del personal ocupado y el 3\% del total de las remuneraciones (INEGI, s/f).
Cancún capta una significativa proporción del total de divisas que ingresan al país, meta que se fijaron los funcionarios de la banca central como herramienta para aliviar el déficit de la balanza de pagos. En 2004 esta entidad captó el 33\% de las divisas que por concepto de turismo ingresaron a México (SEDETUR, 2005), cifra que ha disminuido ligeramente pues de los 11872 millones de dólares que ingresaron al país por concepto de turismo en 2010, Quintana Roo captó 3872 millones de dólares, lo que representa el 32.6\% (SEDETUR, s/f). ${ }^{7}$

La contribución del turismo para aliviar el déficit del sector externo de la economía ha venido a la baja. Entre los años 1987 y 1997 disminuyó su participación en la balanza de pagos de 9.5\% a 5.8\% (Brenner, 2002: 507). En el lapso de 2002 a 2010, los ingresos generados por los viajeros internacionales representaron en promedio $4 \%$ del total de los egresos - bienes y servicios- de la economía mexicana (Banco de México, 2011: 115, 120). Además, el potencial del turismo para atraer divisas palidece cuando se compara con el generado por otras actividades productivas. En los años noventa del siglo pasado, por ejemplo, los productos industriales terminados - automóviles, electrodomésticos o productos químicos, entre otros - generaron un 60\% del total del ingreso de divisas (Brenner: 2007: 16). Recientemente, de 2002 a 2010, la proporción de los ingresos por concepto exclusivamente de bienes mercancías generales - respecto del total de egresos -bienes y servicios-, promedió 81.9\% (Banco de México, 2011: 115, 120).

La construcción de Cancún y su posterior crecimiento atrajeron fuertes corrientes de inmigrantes, quienes se emplearon en la construcción, en la hotelería, en la industria restaurantera, o en los servicios de apoyo o complementarios, como agencias de viajes o de transportación. Debe considerarse, sin embargo, que la gran mayoría de los empleos que se han generado son de baja calificación y de carácter temporal; a nivel nacional, por ejemplo, el número más elevado de ocupaciones dentro del sector corresponde a "fonderos, cantineros, 
meseros y azafatas", que representan el 41.5\% del total (Secretaría del Trabajo y Previsión Social, 2009). De hecho, una proporción significativa de la población económicamente activa del municipio de Benito Juárez cuenta con bajos niveles de instrucción; el 19.4\% tiene estudios de primaria, el $26.6 \%$ de secundaria y un $6 \%$ no tiene estudios, lo que arroja un 52\% del total (Ayuntamiento de Benito Juárez, 2011: 15).

Los datos oficiales sobre población ocupada en Cancún indican que se cumplió el propósito de proveer empleo. Por ejemplo, en 2010 Cancún registró una población ocupada de $93.3 \%$, una cifra muy similar a la que tuvieron las ciudades de La Paz (93.5\%) o Tlaxcala (93.2\%) (INEGI, s/f). Aun cuando este dato no es significativo comparativamente hablando, lo es si se examinan con más detalle las percepciones salariales de la población laboral de Cancún. En 2010, este polo turístico tuvo un mayor porcentaje de población ocupada cuyos ingresos se ubicaron en los rangos de entre dos y cinco salarios mínimos (52\%), posicionándose por arriba de urbes como Guadalajara (44.6\%), Ciudad de México (42.2\%), Acapulco (38.8\%) y Oaxaca (42\%) (INEGI, s/f). Sin embargo, la Encuesta Costo de Vida Nacional 2010, de la empresa consultora Mercer, situó Cancún como la tercera ciudad más cara a nivel nacional, después de Monterrey y Los Cabos, dejando al Distrito Federal en cuarto lugar de la lista (Mercer, 2010).

Como se puede apreciar, Cancún se posiciona mejor que otras ciudades del país en lo referente a los ingresos percibidos por la población. Por ejemplo, en el 2010 la principal urbe turística del Caribe mexicano tuvo el menor porcentaje de población ocupada sin recibir ingresos (3\%) y la mayor proporción de los que ganan más de cinco salarios mínimos (18\%), dejándola mejor ubicada que la Ciudad de México (3.3\% y 9.7\%), Guadalajara (4.1\% y 10.4\%), Acapulco (13.9\% y 6.5\%) y Oaxaca (6.65 y 9.4\%) (INEGI, s/f). Estos hechos destacables han de juzgarse, sin embargo, frente a otros fenómenos económicos que afectan al estado y su zona norte en especial: la tendencia a la baja en la capacidad de compra de los salarios y la temporalidad del empleo así como su precariedad. Según el Consejo Nacional de Evaluación de la Política de Desarrollo Social, con un incremento mayor al 30\% del Índice de la Tendencia Laboral de la Pobreza (ITPL) "Quintana Roo... se encuentra entre las cinco entidades que más aumentaron su población que no puede adquirir una canasta básica de alimentos con el ingreso de su trabajo" (Cruz, 2011: 2). Por otro lado, como reconoce el Delegado de la Secretaría del Trabajo y Previsión Social en Quintana Roo, empresas asentadas en los municipios turísticos del estado fuerzan a sus trabajadores a tomar vacaciones sin goce de sueldo en las temporadas bajas. Se calcula que en la temporada baja de septiembre de 2011 se perdieron cinco mil empleos, 90\% de los cuales eran posiciones eventuales y el resto permanentes (Rosas, 2011: 3). Esta situación de la fuerza laboral explica en buena medida que Quintana Roo ocupe el cuarto lugar nacional en empleo informal (Ayuntamiento de Benito Juárez, 2011: 15).

Con el desarrollo de la industria turística, Cancún se fue transformando en un gran centro urbano en cuyo espacio se han asentado personas provenientes de zonas rurales, de otras entidades del país y el extranjero. Desde sus comienzos, sin embargo, se pudo observar cómo se iba conformando una ciudad con marcadas divisiones sociales, toda vez que se privilegiaba con una infraestructura de buena calidad a la zona hotelera y a aquella en donde se establecería la población de ingresos medios y altos. Así, se confirma que, en su concepción original, el Centro Integralmente Planeado dejó fuera del esquema y de su visión de urbe turística a los estratos sociales más desfavorecidos. Como narra Fernando Martí en su obra Cancún, fantasía de banqueros: Alfonso Alarcón, responsable del proyecto de ciudad por parte de INFRATUR, explicó a Antonio Enríquez Savignac, el entonces director del organismo, que la masiva llegada de trabajadores y colonos estaba creando "un núcleo precarista que ni en 20 años íbamos a regularizar" 
(Martí, 1985: 5l). De las localidades que se formaron a consecuencia de una ocupación informal del espacio, destacan las ubicadas en el ejido Alfredo V. Bonfil, "en donde en general la población carece de servicios urbanos y equipamiento básico" (Municipio de Benito Juárez, 2007: 14). A finales del siglo XX se calculó que el 80\% de la población que vivía en Cancún habitaba en las llamadas Regiones, es decir, áreas de asentamiento populares (Arriaga, 2000: 81). No obstante ello, es de suponerse que no todas las llamadas Regiones comparten los mismos niveles de carencia, pues según el Consejo Estatal de Población de Quintana Roo (COESPO), en 2010 el municipio de Benito Juárez se clasificó como de grado de marginación "muy bajo" (COESPO, s/f).

\section{Conclusión}

Al hacer un examen de los objetivos que se plantearon los funcionarios del Banco de México con la puesta en marcha de un polo turístico en la costa del Caribe mexicano, es evidente que se consiguieron algunos de los propósitos delineados: se han creado puestos de trabajo, generado divisas y nació una urbe en un punto prácticamente deshabitado del territorio nacional. Sin embargo, no se alcanzó la integración económica de la región, cuando se constata que Cancún tiene poca relación productiva con el área circundante y la base material del estado descansa excesivamente en el sector turismo. El primero de los Centros Integralmente Planeados que impulsó el gobierno federal atrajo fuertes corrientes de inmigrantes de otros estados del país, quienes encontraron empleo en la pujante industria turística del destino. Más importante aún, los ingresos de la población ocupada de este centro de recreo lo sitúan en una posición destacada a nivel nacional. No obstante ello, se observa que la informalidad, la estacionalidad y la precariedad del empleo vulneran la vida de los trabajadores del ramo turístico cancunense.
Cancún es un claro ejemplo de una concepción del desarrollo o progreso que se explica a partir "de objetos inanimados de convivencia” (Sen, 2010: 255), como el PIB y demás datos estadísticos, que miden el bienestar "por el tamaño de la suma total de utilidad creada" (Sen, citado en Reyes Escobar, 2009: 23). El objetivo de este estudio no ha sido el contrastar perspectivas sobre el despegue o progreso económico, sino explicar las razones o revelar las fuerzas detrás del surgimiento del proyecto Cancún. Al hacer esto, sin embargo, puede argumentarse que los funcionarios del Banco de México que a fines de los años sesenta del siglo XX impulsaron la construcción de los llamados Centros Integralmente Planeados, optaron por una fórmula económica de desarrollo que, de un lado, se concentró en un sector considerado clave o estratégico y, del otro, procuró "incorporar las regiones que... han ido quedando atrás en el proceso" (Medina, 1964: 117). En suma, a 42 años del nacimiento de Cancún, la valoración que aquí se hace del ideal y objetivos que procuraron alcanzar los promotores de este polo turístico resulta en una imagen en la que se mezclan innegables logros y evidentes dificultades que contravienen los propósitos iniciales del proyecto.

\section{Notas}

'Arriaga (2000) analiza el fenómeno de la informalidad en Cancún, en tanto Ken (2000) hace un breve examen de sus efectos económicos. Sierra Sosa (2006) ha estudiado desde una perspectiva antropológica la migración maya a Cancún, mientras que el trabajo sobre esta ciudad turística compilado por Macías Richard y Pérez Aguilar (2009) contiene aportaciones de distintos investigadores a los temas del desarrollo urbano (Romero, 2009), medio ambiente (Fernández de Lara, 2009) y la cultura (Pérez y Ramos). Jiménez Martínez y Sosa (2008) destacan la débil integración personal, familiar y social como uno de los impactos más significativos del crecimiento de Cancún, y 
Castillo (2011) analiza la segregación social en la ocupación de los espacios de la ciudad, encontrando una relación entre calidad de vida y distancia de la zona hotelera.

${ }^{2}$ El apoyo al establecimiento de una industria nativa tomó forma en distintas políticas y programas gubernamentales cuya implementación se extendió alrededor de cuarenta años. La última de estas acciones y que marca la conclusión de este esfuerzo deliberado por promover el sector industrial del país, fue la Alianza para la Producción, la cual funcionó razonablemente bien hasta 1980, dos años antes de que culminara la administración del presidente José López Portillo (Tello, 2007: 552-553).

3 La modernización tiene rasgos socio-demográficos que la distinguen. Supone un proceso por el cual un importante conjunto de obligaciones tradicionales de tipo social, económico y psicológico se erosionan y rompen, y las personas quedan expuestas a nuevos patrones de socialización y comportamiento. En la esfera económica, la modernización implica el desarrollo de una tecnología avanzada impulsada por la aplicación del conocimiento en las ocupaciones de los sectores secundario -industrial y comercial- y terciario - servicios - en lugar de las de tipo primario y extractivas (Eisenstadt, 1966: 2-3)

${ }^{4}$ En la década de los cincuenta del siglo XX, economistas como Simon Kuznets llevaron a que en la teoría del desarrollo se estableciera como un lugar común "la idea de que en el largo plazo eran convergentes el crecimiento y la distribución equitativa del ingreso... La hipótesis Kuznets... supone que primero se crece y después se distribuye, es decir, que en la etapa inicial del crecimiento, los grupos en desventaja sufren penalidades mientras los ricos aumentan la tasa de ahorro..." (Ávila, 2009: 163).

5 A Antonio Enríquez Savignac, cercano colaborador de Ernesto Fernández Hurtado en el Banco Central, y principal responsable del diseño y puesta en marcha del primero de los cinco Centros Integralmente
Planeados, Cancún, "le llevó 18 meses recorrer las principales cuencas turísticas, concentrándose en las que representaban competencia directa para los atractivos mexicanos: Florida, Hawaii y el Caribe" (Fondo Nacional de Fomento al Turismo, 2010: 19). Pedro Dondé Escalante, también figura destacada de ese equipo del Banco de México, realizó, entre otros estudios, "un análisis comparativo de la demanda del turismo extranjero para destinos de playa, dimensionada respecto a ciudades históricas o coloniales y sitios arqueológicos" (Dondé y Turrent, 2009: 18).

6 "La Riviera Maya se extiende a lo largo de la costa Noreste de la Península de Yucatán en el Estado de Quintana Roo, con una superficie de 181,831 ha, desde Playa Secreto, al sur de Puerto Morelos, Norte de Playa del Carmen, hasta Punta Allen en la zona norte de la Reserva de la Biosfera de Sian Ka an. Comprende más de 22 microdestinos turísticos y alberga las zonas arqueológicas de Tulum y Cobá, parques temáticos como Xcaret y Xel-Ha, parte de la segunda barrera arrecifal más grande del mundo (la Mesoamericana), una fracción de la Biosfera de Sian Ká an, el Santuario de la Tortuga Marina Xcacel- Xcacelito, sistemas de aguas subterráneas con cuevas, cavernas y cenotes, y numerosos destinos de playa, como la Ciudad de Playa del Carmen" (Programa de las Naciones Unidas para el Medio Ambiente, 2008: 32).

7 En 2011 México ocupó la décima posición en la lista de los principales países receptores de turistas internacionales (World Tourism Organization, 2012: 6), aunque se posicionó en el lugar número 23 entre las naciones que obtienen mayores ingresos por turismo (Secretaría de Turismo, 2011).

\section{Bibliografía}

Arriaga, Juan Carlos (2000), "Sector informal y economía del turismo en Cancún”, en Maerk, 
Johannes e Ian Boxill (coord.), Turismo en el Caribe. Tourism in the Caribbean, México: Universidad de Quintana Roo/University of West Indies/Plaza y Valdés, pp. 67-91.

Ávila, José Luis (2009), "La desigualdad económica. Notas para una (re)discusión”, en Di Castro, Elisabetta (coord.) Justicia, desigualdad y exclusión. Debates contemporáneos, México: Universidad Nacional Autónoma de México, pp. 151-174.

Ayuntamiento de Benito Juárez (2011), Plan municipal de desarrollo 2011-2013, México: el ayuntamiento.

Banco de México (2011), Informe anual, México: el Banco.

Brenner, Ludger (2002), "Luxury Tourism and Regional Economic Development", en The Professional Geographer, núm. 54 (4), pp. 500-520.

Brenner, Ludger (2005), "State-Planned Tourism Destinations: The Case of Huatulco, Mexico", en Tourism Geographies (7) 2, pp. 138-164.

Brenner, Ludger (2007) “La política turística mexicana y su impacto en el desarrollo nacional y urbanoregional", en Campos Cámara, Bonnie (coord.), Urbanización y turismo, México: Universidad de Quintana Roo/Ediciones Pomares, pp. 13-24.

Careaga Viliesid, Lorena (1990), Quintana Roo. Una historia compartida, México: Instituto de Investigaciones Dr. José María Luis Mora.

Castillo Pavón, Octavio (2011), “Segregación socioespacial en Cancún: 1990-2010, tres ciudades en una misma", en Provincia, núm. 26, julio septiembre, pp. 11-31.

César Dachary, Alfredo y Stella Maris Arnaiz Burne (1998), El Caribe mexicano. Una frontera olvidada, México: Universidad de Quintana Roo.

Cruz, Osiris (2011), "Crece pobreza en Q. Roo por bajos salarios", en Novedades de Quintana Roo, 4 de diciembre, p. 2.

Dondé Escalante, Pedro y Eduardo Turrent y Díaz (2009), Banco de México. Fundador de Cancún. XL aniversario: 1969-2009, México: Banco de México.
Eisenstadt, S.N. (1966), Modernization: protest and change, Englewood Cliffs: Prentice Hall.

Enríquez, Rosario (1988), "The rise and collapse of stabilising development", en Philip, George (ed.), The Mexican economy, Londres: Routledge, pp. 8-40.

Erfani, Julie A. (1995), The paradox of the Mexican state. Rereading sovereignty from independence to NAFTA, Boulder: Lynne Rienner Publishers.

Fernández Christlieb, Paulina y Octavio Rodríguez Araujo (1985), La clase obrera en la historia de México. Acumulación de capital, estado y clase obrera en el sexenio de Tlatelolco (1964-1970), México: Siglo XXI.

Fernández de Lara Gaitán, Alfredo (2009), "Cancún. Las contradicciones socioambientales de un desarrollo turístico integralmente planeado: 19702000", en Macías Richard, Carlos y Raúl Arístides Pérez Aguilar (comp.), Cancún. Los avatares de una marca turística global, México: Universidad de Quintana Roo/Bonilla Artigas Editores, pp. 163224.

Fondo Nacional de Fomento al Turismo (1988), Tourist resorts. A Mexican strategy for development. A record on the creation of five integral touristic resorts: the imprint of Fonatur on the geography of Mexico, México: FONATUR.

Fondo Nacional de Fomento al Turismo (2010), FONATUR 35 años. Una historia narrada por sus fundadores y protagonistas, México: FONATUR.

Gollás, Manuel y Adalberto García Rocha (1976), "El desarrollo económico reciente de México”, en W. Wilkie, James, Michael C. Meyer y Edna Monzón de Wilkie (ed.), Contemporary Mexico. Papers of the IV International Congress of Mexican History, Berkeley: University of California Press, pp. 405-440.

Hamnett, Brian (1999), A concise history of Mexico, Cambridge: Cambridge University Press.

Hansen, Rogar (1978), La política del desarrollo mexicano, México: Siglo XXI.

Hellman, Judith Adler (1978), Mexico in crisis, Londres: Heinemann. 
Hernández Chávez, Alicia (2002), México. Una breve historia. Del mundo indígena al siglo XX, México: Fondo de Cultura Económica.

INEGI (Instituto Nacional de Estadística, Geografía e Informática) (1980), X censo general de población y vivienda 1980, México: INEGI.

INEGI (1990), XI censo general de población y vivienda 1990, México: INEGI.

INEGI (2000), Perfil sociodemográfico Quintana Roo. XII censo general de población y vivienda 2000, México: INEGI.

INEGI (2000a), XII censo general de población y vivienda 2000, México: INEGI.

INEGI (2003), Cuaderno estadístico municipal de Benito Juárez, Quintana Roo, México: INEGI.

INEGI (2006), Cuaderno estadístico municipal. Benito Juârez, Quintana Roo, México: INEGI.

INEGI (2009), “Censos económicos 2009”, México: INEGI. 〈http:www.inegi.org.mx/est/contenidos/ español/proyectos/censos/ce2009/calc-CENSALmunicipio.asp> [29 de junio de 2012].

INEGI (2010), Principales resultados del censo de poblacióny vivienda 2010. Quintana Roo, México: INEGI.

INEGI (2010a), XIII censo general de población y vivienda 2010, México: INEGI.

INEGI (2010b), Censo de población y vivienda, México: INEGI.

INEGI (2011), Perspectiva estadística Quintana Roo. Diciembre 2011, México: INEGI.

INEGI (s/f), "Encuesta nacional de ocupación y empleo. Consulta interactiva de indicadores estratégicos (InfoLaboral)", México: INEGI. 〈http:www. inegi.org.mx/sistemas/infoenoe/tripreliminar. aspx?c=27736\&=est $>$ [11 de julio de 2012].

Jiménez Martínez, Alfonso de Jesús y Ana Priscila Sosa Ferreira (2008), "Cocktail Cancún: reflexiones sobre los impactos sociales del turismo en la comunidad local", en Perspectivas, núm. 3, pp. 1-43.

Ken, Crucita (2000), "El impacto económico del turismo en Cancún: un acercamiento teórico y metodológico de su estudio", en Maerk, Johannes e Ian Boxill (coord.), Turismo en el Caribe. Tourism in the Caribbean México: Universidad de Quintana Roo/ University of West Indies/Plaza y Valdés, pp. 149163.

Lickorish, Leonard J. y Carson L. Jenkins (2000), Una introducción al turismo, Madrid: Síntesis.

Lozano, René (2010), “El PIB municipal en Quintana Roo", en Universidad de Quintana Roo, México. 〈http//:cemopre.ecouqroo.com〉 [4 de julio de 2012]. Macías Richard, Carlos y Raúl Arístides Pérez Aguilar (2009), Cancún. Los avatares de una marca turística global, México: Universidad de Quintana Roo/ Bonilla Artiga Editores.

MacDonald Escobedo, Eugenio (1981), Turismo: una recapitulación. Historiografía de los conceptos pronunciados por gobernantes mexicanos desde 1823, México: Bodoni.

Martí, Fernando (1985), Cancún. Fantasía de banqueros, México: Editorial Uno.

Medina Echavarría, José (1964), Consideraciones sociológicas sobre el desarrollo económico de América Latina, Buenos Aires: Ediciones Solar.

Mercer (2010), "Presenta Mercer su Encuesta Costo de Vida Nacional 2010", México: Mercer. $\langle$ http//:latam.mercer.com/press-releases/1413630〉 [16 de julio de 2012].

Municipio de Benito Juárez (2007), Plan estratégico de desarrollo sustentable. Municipio de Benito Juárez. Documento síntesis, México: el municipio.

Ortiz, Guillermo (2009), "Presentación", en Dondé Escalante, Pedro y Eduardo Turrent y Díaz. Banco de México. Fundador de Cancún. XL Aniversario: 1969. 2009, México: Banco de México, p. 9.

Pérez Aguilar, Raúl Arístides (2009), "Cancún: imaginarios y usos del espacio urbano", en Macías Richard, Carlos y Raúl Arístides Pérez Aguilar (comp.), Cancún. Los avatares de una marca turística global, México: Universidad de Quintana Roo/ Bonilla Artigas Editores, pp. 325-392. 
Programa de las Naciones Unidas para el Medio Ambiente (2008), Perspectivas del medio ambiente: GEO Playa del Carmen, México: PNUMA/Ayuntamiento de Solidaridad.

Ramos Díaz, Martín (2009), “iPor qué crear el Centro Cultural Cancún? Apuntes para un proyecto de política cultural local", en Macías Richard, Carlos y Raúl Arístides Pérez Aguilar (comp.), Cancún Los avatares de una marca turística global, México: Universidad de Quintana Roo/Bonilla Artigas Editores, pp. 393-435.

Reyes Escobar,Jorge Armando (2009), "Justicia, desigualdad y exclusión. La no-impertinencia de la filosofía", en Di Castro, Elisabetta (coord.), Justicia, desigualdad y exclusión. Debates contemporáneos, México: Universidad Nacional Autónoma de México, pp. 19-49.

Romero Mayo, Rafael (2009), "Política municipal y desarrollo urbano de un modelo turístico. Cancún: 1975-2002", en Macías Richard, Carlos y Raúl Arístides Pérez Aguilar (comp.), Cancún. Los avatares de una marca turística global, México: Universidad de Quintana Roo/Bonilla Artigas Editores, pp. 15-162.

Rosas, David (2011), "Deja la temporada baja a más de 5 mil personas sin empleo", en El Quintanarroense, 20 de septiembre, México, p. 3.

Secretaría de Desarrollo Social (2004), Cancún, Quintana Roo. Estudios urbanísticos y ambientales en 75 barrios correspondientes a 31 ciudades del Sistema Urbano Nacional (SUN). Barrios D55, Regiones 220 y 221. D 56 Región 219, México: SEDESO.

Secretaría de Turismo (s/f), "Principales indicadores en operaciones de aeropuertos. Cancún, Ciudad de México. Reporte anual: 1988-2010", México: SEDETUR. 〈http://datatur.sectur.gob.mx/portal/Datatur2/ reporteadorDespliega.do> [20 de junio de 2012].
Secretaría de Turismo (s/fa), "Principales indicadores en hoteles y moteles de Cancún. Reporte anual: 2007", México: SEDETUR. 〈http://datatur.sectur. gob.mx/portal/Datatur2/reporteadorDespliega.do> [28 de junio de 2012).

Secretaría de Turismo (2011), Compendio estadístico del turismo en México, México: SEDETUR.

Secretaría de Turismo del Estado de Quintana Roo (2005), Programa sectorial 2005-2011, México: SEDETUR.

Secretaría de Turismo del Estado de Quintana Roo (s/f), "Indicadores turísticos 201l", México: SEDETUR. 〈http://sedetur.qroo.gob.mxIndex.php/estadisticas/ indicadores-turisticos> [28 de junio de 2012].

Secretaría del Trabajo y Previsión Social (2009), "Panorama Anual del Observatorio Laboral Mexicano. Panorama de la ocupación por sector económico. Servicios personales-turismo", México: la Secretaría. 〈http:// observatoriolaboral.gob.mx/work/sites/ola/resources/ LocalContent/809/3/POSE2.pdf> [12 de julio de 2012].

Sen, Amartya (2010), La idea de la justicia, México: Santillana Ediciones.

Sierra Sosa, Ligia (2006), "Un acercamiento a los conceptos de migración y mercado de trabajo en un contexto urbano", en Sierra Sosa, Ligia y Julio Robertos Jiménez (coord.) Migración, trabajo y medio ambiente. Acercamientos teóricos en las ciencias sociales desde el Caribe mexicano, México: Universidad de Quintana Roo/Plaza y Valdés, pp. 133-177.

Solís, Leopoldo (1983), La realidad económica mexicana. Retrovisión y perspectivas, México: Siglo XXI.

Tello, Carlos (1980), La política económica en México, 19701976, México: Siglo XXI.

Tello, Carlos (2007), Estado y desarrollo: México 19202006, México: Universidad Nacional Autónoma de México. 
Villarreal, René (1977), "The Policy of ImportSubstituting Industrialization, 1929-1975”, en Reyna, José Luis y Richard S. Weinert (eds.), Authoritarianism in Mexico, Philadelphia: Institute for the Study of Human Issues, pp. 67-107.
World Tourism Organization (2012), UNWTO Tourism Highlights. 2012 Edition, Madrid: WTO.

Wilkie, James W. (1970), The Mexican revolution: federal expenditure and social change since 1910, Berkeley: University of California Press. 